\title{
Predictors of Early Antenatal Care Booking in Government Health Facilities of Hossana Town, Hadiya Zone, South Ethiopia: Unmatched Case Control Study
}

\section{Belayneh Hamdela ${ }^{1 *}$, Girma Godebo ${ }^{2}$ and Tsegaye Gebre ${ }^{3}$}

${ }^{1}$ Department of Public health, Faculty of medicine and health sciences, Wachemo University, Ethiopia

${ }^{2}$ Department of Medicine, Faculty of medicine and health sciences, Wachemo University, Ethiopia

${ }^{3}$ Department of Nursing, Faculty of medicine and health sciences, Wachemo University, Ethiopia

\begin{abstract}
Background: Early entry to antenatal care is important for early detection and treatment of adverse pregnancy related outcomes. However, only $11 \%$ of Ethiopian women had an antenatal care visit before their fourth month of pregnancy, as recommended by world health organization. Hence, this study was aimed to assess predictors of early ante natal booking in government health facilities of Hossana town, Hadiya zone, South Ethiopia.
\end{abstract}

Methods: Health facility based an unmatched case control study was conducted in government health facilities in Hossana town, from December, 1/2014-April, 30/2015 using interviewer guided questionnaire. Total sample size was 255 (85 cases and 170 controls) and taken from all government health facilities in case to control ratio 1:2 until the total sample of cases and controls obtained. Bivariate regression analysis was done and all explanatory variables associated with early ANC booking at $p$-value $<0.25$ were entered in to multivariable logistic regression analysis. Finally, p-value $<0.05$ was used to identify independent predictors of early antenatal booking.

Results: Visiting antenatal care alone [Adjusted Odds Ratio (AOR) $=3.43(95 \%$ confidence interval (Cl: 1.06, 11.09)], being employed in non-governmental organizations [AOR=6.82(95\% $\mathrm{Cl}: 1.56,29.77)]$, venders $[\mathrm{AOR}=6.25(95 \% \mathrm{Cl}$ : $2.16,18.06)]$, housewife $[\mathrm{AOR}=3.3(95 \% \mathrm{Cl}: 1.09,9.97)]$, perceived time of antenatal care initiation at $\leq 4$ months of pregnancy $[A O R=5.51(95 \% \mathrm{Cl}: 1.28,23.67)]$, recognition of pregnancy at $1-2$ months $[\mathrm{AOR}=7.21(95 \% \mathrm{Cl}: 2.47$, $21.08)]$ and perceived number of 4 and more antenatal care visit per pregnancy [AOR=3.53(95\% $\mathrm{Cl}: 1.22,10.21)]$ were independent predictors of early antenatal care booking among pregnant women attending antenatal care unit in government health facilities of Hossana town.

Conclusions and recommendations: Health service managers, health care providers, Medias and community at large should give emphasis for the predictors of early antenatal booking like number of antenatal care visit per pregnancy, early recognition of pregnancy and time of antenatal care initiation to improve early antenatal care booking and to enable women benefit from the services in Hossana town.

Keywords: Predictors; Early antenatal care booking; Pregnant women

\section{Background}

Maternal health care service is crucial and one of the most effective health interventions to improve the general health status of women particularly in places where women empowerment, equity and decision making regarding their own health and about their children is low [1]. In developing countries like Ethiopia as result of low utilization of maternal health care service such as antenatal care visit (34\%), skilled delivery care (10\%) and post natal care (7\%); the opportunity to deliver health information and services that can significantly promote the health of the women and their infants is one of the challenges that the government is facing. Further explanation for lower utilization of modern health services by a sizable proportion of women in the country are: modern contraceptive use $27 \%$, an unmet need for family planning $25 \%$ and twelve month contraceptive discontinuation rate for all methods $37 \%$. More, $17 \%$ of women took iron supplements during pregnancy, $6 \%$ took intestinal parasite drugs and one in five women was informed of signs of pregnancy complications during an antenatal care visit [2].

As a result, maternal mortality and morbidity are one of the highest in the world (676/100000 live births) [1,2]. To optimize the effectiveness of maternal health services, early entry to antenatal care is crucial since women visiting antenatal care receive counseling on the importance of skilled care delivery and subsequent post natal checkups. More, early entry to antenatal care is important for early detection and treatment of adverse pregnancy related outcomes. Thus, world health organization (WHO) recommended that pregnant women in developing countries should seek antenatal care within the first four months of pregnancy while in developed countries such as the United Kingdom and the United States, antenatal care is recommended within the first 12 weeks of pregnancy [3]. However, only $11 \%$ of Ethiopian women had an antenatal care visit before their fourth month of pregnancy, as recommended and $19 \%$ received the recommended four or more antenatal care visits [2].

Early initiating antenatal care has many benefits for women in general and teenagers in particular. For instance, first comprehensive health assessments including maternal baselines such as weight, blood

*Corresponding author: Belayneh Hamdela, Department of Public health, Faculty of medicine and health sciences, Wachemo University, Hossana, South 667, Ethiopia, Tel: +251945845544; Fax: +251465551930; E-mail: belaynehhamdala@ yahoo.com

Received October 06, 2015; Accepted Novmeber 16, 2015; Published November 23, 2015

Citation: Hamdela B, Godebo G, Gebre T (2015) Predictors of Early Antenatal Care Booking in Government Health Facilities of Hossana Town, Hadiya Zone, South Ethiopia: Unmatched Case Control Study. J AIDS Clin Res 6: 521 doi:10.4172/2155-6113.1000521

Copyright: (c) 2015 Hamdela B, et al. This is an open-access article distributed under the terms of the Creative Commons Attribution License, which permits unrestricted use, distribution, and reproduction in any medium, provided the original author and source are credited. 
pressure and urinalysis will be assessed. Pregnant women especially teenagers will be informed about how to recognize and respond to the signs of obstetric complications as they may have little knowledge and experience in reproductive health and tetanus toxoid immunization which is lifesaving both for the mother and infant will be initiated early. Birth preparedness and complication readiness plan will be arranged and counseling on the importance of iodized salt consumption will be offered. Supplementation of pregnant women, who are at risk of nutritional deficiency with folic acid up to 12 weeks of gestation, reduces the risk of having a baby with neural tube defects such as anencephaly and spinal bifida [4]. More, treatment of malaria, anemia, STIs and prevention of mother to child transmission of HIV can be addressed if early antenatal care initiations made [5-7]. These health benefits are enhanced among socially disadvantaged, high risk populations that usually experience difficulty in obtaining adequate antenatal care. Hence early antenatal care booking is a strong predictor of positive pregnancy outcomes, and has a substantial impact on maternal and child mortality [8].

Studies reported that maternal education, younger age, first pregnancy, lower parity, planned pregnancy, previous history of still birth, previous early antenatal care visit, perceived number of four antenatal care visit, advice on early antenatal care visit were associated with early antenatal care booking $[4,6,7,9,10]$. There are few literatures available in Ethiopia which was conducted on factors affecting antenatal care utilization, maternal health care service and timing of antenatal care $[1,4,5,9]$ but no study on early antenatal care booking conducted yet in the area. Therefore, this study using Andersons health seeking behavior model application, will attempt to identify independent predictors of early antenatal care booking in the study area so as to implement interventions.

\section{Conceptual framework}

Based on the reviewed literature, the predisposing, enabling as well as the need factors associated with early ante natal care booking was identified below in conceptual frame work. The conceptual frame work was adapted from the Andersons health seeking behaviour model which was used by many of researchers on factors related with health service utilization $[4,6,7,9]$ (Figure 1).

\section{Method and Materials}

Health facility based unmatched case control study was conducted from December, 1/2014 to April, 30/2015, in Hossana town government health facilities, Hadiya zone, South Ethiopia. Hossana town is located $230 \mathrm{~km}$ far from Addis Ababa, and $194 \mathrm{~km}$ from regional city Hawassa. It is the capital town of Hadiya zone. It is one of the eleven districts found in the zone. It has purely woinedega agro ecological zone. It is situated at an altitude of 1800-2950 meters above sea level and has an average temperature ranging from $10^{\circ} \mathrm{C}$ to $24^{\circ} \mathrm{C}$. The annual rain fall is $1250 \mathrm{~mm}$ per year. Based on the 2007 Ethiopian national population and housing census the population of the town is projected to be about 78,432 : male 38,800 and female 39,632 . Number of child bearing age women (15-49 years) is 18,275 . There is one zonal referral hospital and three health centers in the town (Hossana town administrative office report). Data was collected from December 2014 -April 2015G.C.

The target population for the study was all pregnant women who were booking for first ante natal care at antenatal care units in government health facilities of Hossana town while the study population was sample of pregnant women who were selected for the study from antenatal care unit in their first visit.
Cases defined as pregnant women who visit antenatal care unit at less than or equal to three months $(=<12$ weeks) of pregnancy. Controls defined as pregnant women who visit antenatal care unit after three months (>12weeks) of pregnancy. In both cases and controls the first antenatal care visit for the recent pregnancy was considered.

Inclusion criteria for both cases and controls were pregnant women who has come antenatal care unit seeking the services that offered during antenatal care visit, the first visit for recent pregnancy and fulfills the definition of cases and controls.

Sample size was calculated using proportion of pregnant women who made previous antenatal care first time visit before and at 12 weeks (main exposure variable which gives adequate sample size) among the cases and controls estimated to be $56.9 \%$ and $35.6 \%$ respectively [9]. Using $80 \%$ power, $95 \%$ confidence interval (CI), 2 odds ratio (OR) and case to control ratio of 1:2. The total sample size was 255 ( 85 cases and 170 controls). The following formula was used to calculate the sample size:

$$
n_{1}=n_{2}=\frac{\left(z_{\alpha / 2} \sqrt{2 \overline{p q}}+z_{\beta} \sqrt{p_{1} q_{1}+p_{2} q_{2}}\right)^{2}}{\Delta^{2}} \mid, \bar{p}=\frac{p_{1}+p_{2}}{2}, \bar{q}=1-\bar{p} .
$$

Those pregnant women fulfilling the inclusion criteria for cases and controls were recruited for the study at first antenatal care visit when they appear to begin the service. The cases and controls that were willing to participate during the study period were taken starting from case, one case in every two controls (1:2) consecutively until the proposed sample of cases and controls obtained.

In this study the outcome/dependent variable was time at antenatal care booking having binary outcomes (before and at twelve weeks of gestation). To identify cases and controls from the beginning, the question asked was; does pregnant woman made her first antenatal care visit at before and/or twelve weeks? The response was "yes or no". The variable for which analysis was done is 'yes' (early antenatal care booking). The explanatory/independent variables were sociodemographic, obstetric, women decision making and health facility related characteristics. Socio-demographic characteristics were maternal age, marital status, ethnicity, religion, family size, education and occupation. Data regarding these variables were obtained by forwarding questions to study participants to which category they belongs to. Obstetric characteristics were addressed by asking study participants about gravidity, receiving counseling on time of antenatal care initiation, pregnancy intention, age at first pregnancy, previous antenatal care utilization, child birth complications (stillbirth) and history of abortion. Health facility related characteristics such as

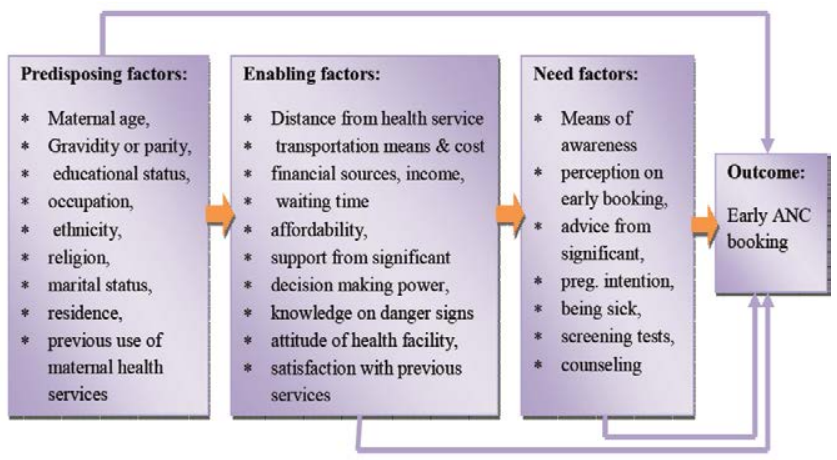

Figure 1. Conceptual frame work for timely use only (adapted from Anderson health seeking behaviour model, 1995). 
distance from their home to the nearest health facility were antenatal care provided, availability of transportation, affordability of transport cost, affordability of service fee, decision making power of women about maternal health service utilization, husband approval of antenatal care visit and about accompanied person during their visits. Knowledge regarding time of antenatal care initiation, number of antenatal care visits were also obtained by forwarding questions to respondents. Both closed and open-ended questions were used to obtain data. For closeended question, yes or no and marking on the list of answer what the respondents answer. For open-ended question, the answers given by the respondents were categorized and recoded in to their appropriate category. Variables were recoded and categorized by using the category of variables in credible sources such as Ethiopian demography and health survey and publications in reputable journals.

Data collection tool or the questionnaire was prepared in English adapted from different literatures $[4,6,7,9,10]$ and translated to Amharic language. Back translation to English was done by another person to check consistence of words and concepts. Data collectors and supervisors were trained on the objective and purpose of the study and role play was done by data collectors to strengthen their skills about how to interview and approach with study participants during data collection. Then instrument was tested on 5\% (24 pregnant women, 8 cases and 16 controls) of the respondents and correction was made accordingly. During data collection, those filled questionnaires were checked by immediate supervisors and rechecked again by the principal investigator before data entry. Data were collected by face to face interview on pregnant women visiting antenatal care unit in their first visit. Four data collectors who are diploma nurses and two supervisors who are master holders in public health were participated.

The collected data were checked manually for their completeness and consistency by supervisors during field work and rechecked again at office before entry. Data were edited, coded and entered to a computer, checked for missing values and outliers and analyzed using SPSS for windows version 16.0 (SPSS Inc. version 16.1., Chicago, Illinois). Descriptive statistic was done to summarize data. Bivariate regression analysis was done to see the association of individual variables to early antenatal care booking at $\mathrm{p}<0.25$. Based on the findings of bivariate regression analysis, variables having significant association with early antenatal care were entered to multivariate logistic regression analysis using the enter method. Finally, $\mathrm{P}<0.05$ in multivariate analysis was used to declare association between independent predictors and early antenatal care booking.

Ethical approval was found from institutional ethical review committee of Wachemo University through faculty of medicine and health sciences. The review committee indicated its ethical approval by writing formal letter to Hossana town health office. Permission also obtained from Hossana town health office before data collection. The purpose, general content, and nature of the investigation were explained to the ethical review committee before field work and for each respondent during data collection. The participants were informed that any information they provide would be kept confidential. The participants were also informed that their responses would not result in any harm to them and given full rights and freedom to participate in the study or not to participate. Participant's name and house number never appeared on data collection tools. Privacy and confidentiality were maintained during interview. Questions and concerns raised by the participants were clarified. Verbal consent was obtained after written consent form read to participants by each data collector. Finally, the participants who agreed to give their full data were included in the study without any coercion.

\section{Results}

\section{Socio-demographic characteristics}

A total of 255 (85 cases and 170 controls) respondents were interviewed. The mean age of cases and controls was 26 with SD of 4.5 and 27 with SD of 4.6 years respectively. Seventy two $(84.7 \%)$ of the cases and $145(85.3 \%)$ of the controls have a family size of 1-4, $13(15.3 \%)$ of the cases and 25(14.7\%) of the controls have a family size of 5 and above. Of 255 respondents, $81(95.3 \%)$ of cases and $168(98.8 \%)$ of controls were married, 1 (1.2\%) of controls were unmarried, $2(2.4 \%)$ of cases and $1(0.6 \%)$ of controls were divorced and $1(1.2 \%)$ of cases and $1(0.6 \%)$ of controls were widowed. Most, 37(43.5\%) of the cases and $62(36.5 \%)$ of the controls were protestant religion followers. Forty two (49.4\%) of the cases and $80(47.1 \%)$ of the controls were from Hadiya ethnic group. Majority, 28(32.9\%) of the cases and 53(31.2\%) controls were attended secondary school (grade 9-12). Majority, 32(37.6\%) of the cases were venders followed by housewife, 29(34.1\%). Among the controls, 71(41.8\%) were housewife while $49(28.8 \%)$ were venders. (See table 1 for detailed socio-demographic characteristics).

\section{Reproductive characteristics}

Twenty one (24.7\%) of the cases and 26(15.3\%) of the controls were primigravida, $53(62.4 \%)$ of cases and $128(75.3 \%)$ of controls were multigravida and the rest $11(12.9 \%)$ of the cases and $16(9.4 \%)$ of the controls were granda multigravida women at the time of interview. Fifty six (65.9\%) of the cases and 110 (65.5\%) of the controls were made antenatal care visit for their previous pregnancy. However, 29(34.1\%) of the cases and 58(34.5\%) of the controls did not made antenatal care visit for their previous pregnancy. Of those who made antenatal care, $27(48.2 \%)$ of the cases and $44(40.7 \%)$ of the controls were made four and more visits for their previous pregnancy. Sixty six (77.6\%) of the cases and $131(77.1 \%)$ of the controls planned their pregnancy at the time of conception. Forty nine (57.6\%) of the cases and 95(55.9\%) of the controls knew being pregnant when their menses is lost, 28(32.9\%) of the cases and 53(31.2\%) of the controls knew being pregnant through laboratory test and the rest $8(9.4 \%)$ of cases and $22(12.9 \%)$ of the controls knew being pregnant through signs and symptoms of pregnancy such as nausea, vomiting, blurred vision, etc. Seventy nine (92.9\%) of the cases and 155(91.2\%) of the controls responded that their pregnancy was approved by support person while $6(7.1 \%)$ of the cases and $15(8.8 \%)$ of the controls responded that their pregnancy was not approved by support persons. Majority of the cases and controls were encouraged to visit antenatal care by support persons [69(81.2\%) versus $145(85.3 \%)$ ]. Seventy eight $(91.8 \%)$ of the cases and $154(91.1 \%)$ of the controls responded that their husbands support antenatal care visit. However, 7(8.2\%) of the cases and 15(8.9\%) of the controls responded that their husbands doesn't support antenatal care visit. Regarding the decision making power for antenatal care visit, 57(67.1\%) of the cases and $115(68 \%)$ of the controls reported that decision about antenatal care visit was made jointly (husband and wife together). Besides, $21(24.7 \%)$ of the cases and $42(24.9 \%)$ of the controls were reported that decision about antenatal care visit was made by themselves. The rest $7(8.2 \%)$ of the cases and $12(7.1 \%)$ of the controls reported that decision about antenatal care visit was made by their husbands. Of the 255 study participants, $60(71.4 \%)$ of the cases and $107(62.9 \%)$ of the controls believed that initiating antenatal care visit before four months has merit. Seventy four (88.1\%) of the cases and 153(92.7\%) 


\begin{tabular}{|c|c|c|}
\hline \multirow{3}{*}{ Socio-demographic characteristics } & \multicolumn{2}{|c|}{ Booked at $=<12$ weeks of gestation? } \\
\hline & Yes (Cases=85) & No (Controls=170) \\
\hline & Frequency (\%) & Frequency (\%) \\
\hline \multicolumn{3}{|l|}{ Age at interview } \\
\hline $15-24$ & $31(37.3)$ & $49(29)$ \\
\hline 25-34 & $47(56.6)$ & 107(63.3) \\
\hline $35-44$ & $5(6)$ & $13(7.7)$ \\
\hline \multicolumn{3}{|l|}{ Religion } \\
\hline Orthodox & 19(22.4) & $41(24.1)$ \\
\hline Protestant & $37(43.5)$ & $62(36.5)$ \\
\hline Muslim & $16(18.8)$ & $30(17.6)$ \\
\hline Catholic & $12(14.1)$ & $31(18.2)$ \\
\hline Others* & $1(1.2)$ & $6(3.5)$ \\
\hline \multicolumn{3}{|l|}{ Ethnicity } \\
\hline Hadiya & $42(49.4)$ & $80(47.1)$ \\
\hline Kenbata & $14(16.5)$ & $25(14.7)$ \\
\hline Gurage & $9(10.6)$ & $20(11.8)$ \\
\hline Silite & $8(9.4)$ & 14(8.2) \\
\hline Amhara & $10(11.8)$ & 19(11.2) \\
\hline Others $^{* *}$ & $2(2.4)$ & $12(7.1)$ \\
\hline \multicolumn{3}{|l|}{ Women's main occupation } \\
\hline Government employee & $10(11.8)$ & $32(18.8)$ \\
\hline NGO employee & $7(8.2)$ & $9(5.3)$ \\
\hline Student & $7(8.2)$ & $9(5.3)$ \\
\hline Vender & $32(37.6)$ & $49(28.8)$ \\
\hline Housewife & $29(34.1)$ & $71(41.8)$ \\
\hline \multicolumn{3}{|l|}{ Husband's main occupation } \\
\hline Farmer & 15(17.9) & $31(18.3)$ \\
\hline Government employee & $21(25)$ & $49(29)$ \\
\hline NGO employee & $6(7.1)$ & $12(7.1)$ \\
\hline Student & $1(1.2)$ & $2(1.2)$ \\
\hline Vender & $41(48.8)$ & $75(44.4)$ \\
\hline \multicolumn{3}{|l|}{ Women's education level } \\
\hline No formal education & $20(23.5)$ & $41(24.1)$ \\
\hline Primary school (grade 1-8) & $23(27.1)$ & $44(25.9)$ \\
\hline Secondary school (grade 9-12) & $28(32.9)$ & $53(31.2)$ \\
\hline Higher education $\left(>12^{\text {th }}\right.$ grade) & $14(16.5)$ & $32(18.8)$ \\
\hline \multicolumn{3}{|l|}{ Husband's education level } \\
\hline No formal education & 14(16.9) & $26(15.5)$ \\
\hline Primary school (grade 1-8) & $21(25.3)$ & $31(18.5)$ \\
\hline Secondary school (grade 9-12) & $26(31.3)$ & $60(35.7)$ \\
\hline Higher education ( $>12^{\text {th }}$ grade) & $22(26.5)$ & $51(30.4)$ \\
\hline
\end{tabular}

Note: Others *=Apoplostic; **= Wolayita, Oromo, Tigre, etc.

Table 1: Socio demographic characteristics of pregnant women attending antenatal care units in governmental health facilities of Hossana town, South Ethiopia, December 2014 -April 2015

of the controls knew the importance of husband and wife testing and counseling during pregnancy. The remained $10(11.9 \%)$ of the cases and $12(7.3 \%)$ of the controls do not knew the importance of husband and wife testing and counseling during pregnancy. Seventy five $(89.3 \%)$ of the cases and $136(82.4 \%)$ of the controls knew that HIV can be transmitted from mother to child. But, $9(10.7 \%)$ of the cases and $29(17.6 \%)$ of the controls do not knew mother to child transmission of HIV. Forty five (53.6\%) of the cases and 63(38.2\%) of the controls knew that mother to child transmission of HIV is preventable. Of those who knew mother to child transmission of HIV is preventable, $12(26.7 \%)$ of the cases and $17(26.9 \%)$ of the controls knew antiretroviral drugs taken during pregnancy could reduce risk of mother to child transmission of HIV. [See table 2 for the detailed reproductive characteristics].

\section{Health facility related factors}

Of the study participants, $72(84.7 \%)$ of the cases and $138(81.2 \%)$ of the controls reported that there are transportation means to health facilities. The rest 13(15.3\%) of the cases and 32(18.8\%) of the controls reported that there are no transportation means to health facilities. Sixty nine $(82.1 \%)$ of the cases and $139(82.2 \%)$ of the controls stated that it might take less than 30 minutes to health facility while $15(17.9 \%)$ of the cases and $30(17.8 \%)$ of the controls stated that it might take 30 minutes and more to arrive at health facilities. Concerning the suitability of the roads, $65(76.5 \%)$ of the cases and $126(74.1 \%)$ of the controls reported that the road is comfortable for transportation. The rest $20(23.5 \%)$ of the cases and $44(25.9 \%)$ of the controls reported that the road is not comfortable for transportation to health facilities. Most of the cases, 79(92.9\%) and controls, 155(91.2\%) responded that they can afford transportation fee. However, $6(7.1 \%)$ of the cases and $15(8.8 \%)$ of the controls responded that they cannot be able to pay transportation fee. Twenty two (26.8\%) of the cases and $40(24.4 \%)$ of the controls had Radio, 13(15.9\%) of the cases and 26(15.9\%) of the controls had Television and 47(57.3\%) of the cases and $98(59.8 \%)$ of the controls had both Radio and Television in their house. Sixty seven (78.8\%) of the cases and $133(78.2 \%)$ of the controls perceive that the health services being provided have quality. The rest $18(21.2 \%)$ of the cases and $37(21.8 \%)$ of the controls perceive that the services being provided in their nearest health facility have no quality.

\section{Predictors of early antenatal care booking}

Binary and multiple logistic regression analysis were done using enter method to analyze factors associated with early antenatal care booking.

On binary logistic regression analysis; accompanied person during

\begin{tabular}{|c|c|c|}
\hline \multirow{3}{*}{ Reproductive characteristics } & \multicolumn{2}{|c|}{ Booked at $=<12$ weeks of gestation? } \\
\hline & Yes $($ Cases $=85)$ & Yes (Cases=85) \\
\hline & Frequency (\%) & Frequency (\%) \\
\hline \multicolumn{3}{|l|}{ Pregnancy intention } \\
\hline Planned & $66(77.6)$ & 131(77.1) \\
\hline Unplanned & $19(22.4)$ & $39(22.9)$ \\
\hline \multicolumn{3}{|l|}{ History of stillbirth } \\
\hline Yes & $8(9.4)$ & $13(7.6)$ \\
\hline No & $77(90.6)$ & $157(92.4)$ \\
\hline \multicolumn{3}{|l|}{ History of abortion } \\
\hline Yes & 11(12.9) & $17(10)$ \\
\hline No & $74(87.1)$ & $153(90)$ \\
\hline \multicolumn{3}{|c|}{ Accompanied person during antenatal care visit } \\
\hline Family & $7(8.2)$ & $28(16.5)$ \\
\hline Friend & 12(14.1) & 26(15.3) \\
\hline Husband & $35(41.2)$ & $72(42.4)$ \\
\hline Alone & $31(36.5)$ & $44(25.9)$ \\
\hline \multicolumn{3}{|l|}{ Place of last child delivery } \\
\hline Home & $18(28.1)$ & $47(32.9)$ \\
\hline Institution & $46(71.9)$ & $96(67.1)$ \\
\hline \multicolumn{3}{|l|}{ Parity } \\
\hline Nullpara & $21(24.7)$ & $28(16.5)$ \\
\hline Primipara & $21(24.7)$ & $48(28.2)$ \\
\hline Multipara & $40(47.1)$ & $87(51.2)$ \\
\hline Grandmultipara & $3(3.5)$ & $7(4.1)$ \\
\hline
\end{tabular}

Table 2. Reproductive characteristics of pregnant women attending antenatal care units in governmental health facilities of Hossana town, South Ethiopia, December 2014 -April 2015 
Citation: Hamdela B, Godebo G, Gebre T (2015) Predictors of Early Antenatal Care Booking in Government Health Facilities of Hossana Town, Hadiya Zone, South Ethiopia: Unmatched Case Control Study. J AIDS Clin Res 6: 521. doi:10.4172/2155-6113.1000521

Page 5 of 7

antenatal care visit, women's main occupation, receiving advice on time of antenatal care initiation from health workers, knowledge of mother to child transmission of HIV, perceived time of antenatal care initiation, knowledge of prevention of mother to child transmission of HIV, gravidity, recognition of pregnancy, perceived number of antenatal care visits and perception of HIV testing and counseling during pregnancy had shown to be associated with early antenatal care booking at $\mathrm{p}$-value $<0.25$.

On multiple logistic regression analysis; women who visited antenatal care alone [AOR=3.43(95\%CI: 1.06, 11.09)], women employed in non-governmental organizations [AOR=6.82(95\%CI: $1.56,29.77)]$, women who are vender [AOR=6.25(95\%CI: 2.16, 18.06)], women who are housewife $[\mathrm{AOR}=3.3(95 \% \mathrm{CI}: 1.09,9.97)]$, perceived time of antenatal care initiation at $\leq 4$ months of pregnancy $[\mathrm{AOR}=$ 5.51(95\%CI: 1.28, 23.67)], recognition of pregnancy at $1-2$ months $[\mathrm{AOR}=7.21(95 \% \mathrm{CI}: 2.47,21.08)]$ and perceived number of 4 and more antenatal care visit per pregnancy $[\mathrm{AOR}=3.53(95 \% \mathrm{CI}: 1.22,10.21)]$ were independent predictors of early antenatal care booking among pregnant women attending antenatal care unit in government health facilities of Hossana town. [Table 3]

\section{Discussions}

A key justification for the prompt referral of women to maternity services is to provide the opportunity to make an informed choice concerning all available antenatal screening options [6].

Provision of antenatal care is included in the three pillars of maternal health care promoted as effective answers to maternal mortality [2]. This service usually provides a range of opportunities for delivering health information and interventions that can significantly enhance health of the mothers. In addition, it also provides entry point to a wide range of programs/interventions such as prevention, control, and treatment of conditions like malaria, mother to child transmission of HIV/AIDS and tuberculosis (TB) that could potentially cause

\begin{tabular}{|c|c|c|c|c|}
\hline \multirow{3}{*}{ Variables } & \multicolumn{2}{|c|}{ Booked at $=<12$ weeks of gestation? } & \multirow{3}{*}{ Crude OR $(95 \% \mathrm{Cl})$} & \multirow{3}{*}{ Adjusted OR $(95 \% \mathrm{Cl})$} \\
\hline & \multirow{2}{*}{ Yes (Cases=85) } & No (Controls=170) & & \\
\hline & & Frequency (\%) & & \\
\hline \multicolumn{5}{|c|}{ Accompanied person during ANC visit } \\
\hline Family & $7[8.2]$ & $28[16.5]$ & 1 & 1 \\
\hline Friend & $12[14.1]$ & $26[15.3]$ & $1.85[0.63,5.41]$ & $2.51[0.67,9.46]$ \\
\hline Husband & $35[41.2]$ & $72[42.4]$ & $1.94[0.77,4.89]^{+*}$ & $1.99[0.64,6.24]$ \\
\hline Alone & $31[36.5]$ & $44[25.9]$ & $2.82[1.09,7.27]^{*}$ & $3.43[1.06,11.09]^{*}$ \\
\hline \multicolumn{5}{|c|}{ Women's main occupation } \\
\hline Gov't employee & $10[11.8]$ & $32[18.8]$ & 1 & 1 \\
\hline NGO employee & $7[8.2]$ & $9[5.3]$ & $2.49[0.74,8.4]^{* * *}$ & $6.82[1.56,29.77]^{*}$ \\
\hline Student & $7[8.2]$ & $9[5.3]$ & $2.49[0.74,8.4]^{* * *}$ & $0.81[0.18,3.57]$ \\
\hline Vender & $32[37.6]$ & $49[28.8]$ & $2.09[0.9,4.83]^{*}$ & $6.25[2.16,18.06]^{*}$ \\
\hline Housewife & $29[34.1]$ & $71[41.8]$ & $1.31[0.57,3]$ & $3.3[1.09,9.97]^{*}$ \\
\hline \multicolumn{5}{|c|}{ Advised to initiate ANC early by health workers } \\
\hline Yes & $54[64.3]$ & $90[52.9]$ & $1.6[0.93,2.74]^{\star \star *}$ & $1.19[0.47,3.01]$ \\
\hline No & $30[35.7]$ & $80[47.1]$ & 1 & 1 \\
\hline \multicolumn{5}{|c|}{ Knew MTCT of HIV } \\
\hline Yes & $75[89.3]$ & $136[82.4]$ & $1.78[0.79,3.95]^{*-}$ & $1.89[0.56,6.42]$ \\
\hline No & $9[10.7]$ & $29[17.6]$ & 1 & 1 \\
\hline \multicolumn{5}{|c|}{ Perceived time of ANC initiation } \\
\hline$\leq 4$ months & $76[95]$ & $132[86.3]$ & $3.02[1,9.13]^{* *}$ & $5.51[1.28,23.67]^{* *}$ \\
\hline$>4$ months & $4[5]$ & $21[13.7]$ & 1 & 1 \\
\hline \multicolumn{5}{|c|}{ Knew PMTCT of HIV } \\
\hline Yes & $45[529]$ & $63[37.1]$ & $1.91[1.13,3.24]^{*}$ & $1.96[0.74,5.19]$ \\
\hline No & $40[47.1]$ & $107[62.9]$ & 1 & 1 \\
\hline \multicolumn{5}{|c|}{ Gravidity } \\
\hline One & $21[24.7]$ & $26[15.3]$ & $1.82[0.95,3.47]^{* *}$ & $2.36[0.89,6.24]$ \\
\hline Two and above & $64[75.3]$ & $144[84.7]$ & 1 & 1 \\
\hline \multicolumn{5}{|c|}{ Recognition of pregnancy } \\
\hline 1-2 months & $76[92.7]$ & $126[75.4]$ & $4.12[1.67,10.17]^{*}$ & $7.21[2.47,21.08]^{*}$ \\
\hline 3 and above & $6[7.3]$ & $41[24.6]$ & 1 & 1 \\
\hline \multicolumn{5}{|c|}{ Perceived number of antenatal care visit } \\
\hline $1-3$ & $9[11.1]$ & $47[30.7]$ & 1 & 1 \\
\hline 4 and above & $72[88.9]$ & $106[69.3]$ & $3.55[1.64,7.69]^{*}$ & $3.53[1.22,10.21]^{*}$ \\
\hline \multicolumn{5}{|c|}{ Perceived husband and wife testing and counseling of HIV during pregnancy } \\
\hline Yes & $74[88.1]$ & $153[92.7]$ & $0.58[0.24,1.41]^{* *}$ & $0.55[0.15,2.0]$ \\
\hline No & 10[11.9] & 12[7.3] & 1 & 1 \\
\hline
\end{tabular}

NB: $1=$ reference category, ${ }^{*}=p$-value $<0.01,{ }^{* *}=p$-value $<0.05,{ }^{* * *}=p$-value $<0.25$, bold $=$ significant association in multiple logistic regression analysis. Adjusted for-Accompanied person, women's main occupation, advised to initiate ANC early, knew MTCT of HIV, perceived time of ANC initiation, PMTCT of HIV gravidity, recognition of pregnancy, perceived number of ANC visit, knew husband and wife testing and counseling during pregnancy.

Table 3. Predictors of early antenatal care booking among pregnant women attending antenatal care units in government health facilities of Hossana town, South Ethiopia, December 2014 -April 2015. 
adverse events to either the woman or her baby [7]. Thus, this health facility based study attempted to assess predictors of early antenatal care booking among pregnant women attending antenatal care units in governmental health facilities of Hossana town.

In this study, women who do not need accompanying person for their antenatal care visit was found to be an important predictor of early antenatal care booking in multivariate analysis. Women who visited antenatal care alone were three times [AOR=3.43(95\%CI: 1.06 , 11.09)] more likely to book antenatal care early than those who need the help of family members. It might be due to the fact that women who already have awareness about the importance of antenatal care visit to the mother and her baby may decide to get the service early. Once the mothers have their own motive to receive antenatal care they may not need the support from the family. It also could be due to women autonomy in decision making regarding maternal health service utilization. According to the Ethiopian demographic and health survey, thirteen percent of currently married women make their own decisions on their own health care, while one woman of every four reported that husband mainly makes such decisions [2]. Empowering women and actively involving them in decision making regarding maternal health service improve the general well being of women and their children.

Employment is one aspect of social life in which gender roles and relationships emerge. It can be a source of empowerment for women; especially if they are in control of the income they generate [2]. In this study, women employed in non-governmental organizations were nearly seven times [AOR=6.82(95\%CI: $1.56,29.77)]$ more likely to book antenatal care early than women employed in governmental organization. Women employed in non-governmental organizations might be able to afford transportation cost or have free/extra time to visit and compensate their task. Women who are vender were six times [AOR=6.25(95\%CI: $2.16,18.06)]$ more likely to book antenatal care early as compared to women employed in governmental organization. Vender women usually work at their own business centers or shops. They themselves control their tasks hence no one punish them when they become absent from work. Thus, they might have freedom and time to visit antenatal care early. Women who are housewife were three times $[\mathrm{AOR}=3.3(95 \% \mathrm{CI}: 1.09,9.97)]$ more likely to book antenatal care early as compared to government employees. This implies that women employed in government institutions might be busy and lack free time to visit antenatal care. In contrary, women who were housewife have free and extra times to go to the health facilities to receive health care like antenatal care. Housewife women also might have time to share with their friends and discuss on the timing and importance of early antenatal care booking.

Women who perceived that antenatal care should be initiated before and at four months of pregnancy were five times $[\mathrm{AOR}=5.51(95 \% \mathrm{CI}$ : $1.28,23.67)]$ more likely to book antenatal care early than those who perceived antenatal care initiation after four months of pregnancy. It implies that educating women about the merits of early initiation will improve early antenatal care booking. Recognition of pregnancy at earlier months will contribute a lot for early antenatal care booking. Accordingly, women who recognized their pregnancy in 1-2 months were seven times $[\mathrm{AOR}=7.21(95 \% \mathrm{CI}: 2.47,21.08)]$ more likely to book antenatal care early than those who recognized their pregnancy after two months. This finding indicates educating women in reproductive ages (15-49 years) about signs and symptoms of pregnancy and a means to be tested should be emphasized. This finding is supported by the study conducted in south-eastern Tanzania in which women who recognized their pregnancy late visited antenatal care late while those who recognized their pregnancy at earlier months utilized antenatal care service early [10].

Perceived number of 4 and more antenatal care visit per pregnancy was shown to be a significant contributing factor for early antenatal care booking. In this regard, women who perceived that antenatal care should be visited four and more times were three times [AOR=3.53(95\%CI: 1.22, 10.21)] more likely to book antenatal care early than women who perceived that antenatal care should be visited for less than four time per pregnancy. This finding shows women who knew the recommended number of antenatal care visits initiate their visit at earlier months in order to receive all recommended services at each visit. This finding is supported with the reported result of University of Gondar Hospital, Northwest Ethiopia in which women who perceived antenatal care visit per pregnancy of four and greater booked antenatal care early [9].

The limitation of this study would be the nature of case control study in which temporal relationship between the presumed cause and effect was difficult to establish. Besides, this study employed face to face interview; it might result in response bias. Furthermore, this study addressed women in government health facilities; it could not be representative of women attending non-governmental health facilities or other sources of antenatal care.

\section{Conclusions and Recommendations}

Findings of this study revealed that visiting antenatal care alone, employment in non-governmental organizations, main occupation being vender and housewife, perceived antenatal care initiation before and at four months of gestation, earlier recognition of pregnancy at 1-2 months and perceived number of four and more antenatal care visit per pregnancy were independent predictors that contributed for early antenatal care booking among pregnant women attending antenatal care units in government health facilities of Hossana town. Thus, programs should aim to enhance utilization of antenatal care early through information and education on factors identified so that pregnant women and their baby benefit from the services which are being provided during each antenatal care visit. Improving women's awareness regarding recommended number of antenatal care visit, time of antenatal care initiation and signs and symptoms of pregnancy to enable women recognize pregnancy by means of health care providers and medias should get due emphasis. Further research should address employment and wealth index to examine the existence of association with early antenatal care booking.

\section{Acknowledgments}

Our deepest gratitude goes to Wachemo University for funding the research project. We are thankful for data collectors and supervisors for their devotion and quality work. We are grateful for Hossana town health administration, health facilities and study participants for their cooperation during the study.

\section{Author Contributions}

Belayneh Hamdela: designed the project proposal. Belayneh Hamdela, Girma Godebo and Tsegaye Gebre: handled overall data collection process. Belayneh Hamdela: done statistical analysis and interpreted the data. Belayneh Hamdela: prepared the manuscript. Belayneh Hamdela, Girma Godebo and Tsegaye Gebre: Read and approved the final manuscript.

\section{Competing interests}

The Authors declared that they have no competing interests exist.

\section{References}

1. Birmeta K, Dibaba Y, Woldeyohannes D (2013) Determinants of maternal health care utilization in Holeta town, central Ethiopia. BMC Health Serv Res 13: 256. 
Citation: Hamdela B, Godebo G, Gebre T (2015) Predictors of Early Antenatal Care Booking in Government Health Facilities of Hossana Town, Hadiya Zone, South Ethiopia: Unmatched Case Control Study. J AIDS Clin Res 6: 521. doi:10.4172/2155-6113.1000521

2. Central Statistical Agency, ICF International (2012) Ethiopia Demographic and Health Survey 2011. Addis Ababa, Ethiopia and Calverton, Maryland, USA: Central Statistical Agency and ICF International.

3. Trinh LT, Rubin G (2006) Late entry to antenatal care in New South Wales, Australia. Reprod Health 3: 8.

4. Alemayehu Tariku, Yilma Melkamu, Zewditu Kebede (2010) Previous utilization of service does not improve timely booking in antenatal care: Cross sectional study on timing of antenatal care booking at public health facilities in Addis Ababa. Ethiopian journal of health development 24: 226-233.

5. Tewodros Alemayehu, Jemal Haidar, Dereje Habte (2010) Utilization of antenatal care services among teenagers in Ethiopia: A cross sectional study. Ethiopian journal of Health Development 24: 221-225.

6. Cresswell JA, Yu G, Hatherall B, Morris J, Jamal F, et al. (2013) Predictors of the timing of initiation of antenatal care in an ethnically diverse urban cohort in the UK. BMC Pregnancy Childbirth 13: 103.
7. Oladokun A, Oladokun RE, Morhason-Bello I, Bello AF, Adedokun B (2010) Proximate predictors of early antenatal registration among Nigerian pregnant women. Ann Afr Med 9: 222-225.

8. Bassani DG, Surkan PJ, Olinto MT (2009) Inadequate use of prenatal services among Brazilian women: the role of maternal characteristics. Int Perspect Sex Reprod Health 35: 15-20.

9. Belayneh T, Adefris M, Andargie G (2014) Previous early antenatal service utilization improves timely booking: cross-sectional study at university of Gondar hospital, northwest Ethiopia. J Pregnancy 2014: 132494.

10. Gross K, Alba S, Glass TR, Schellenberg JA, Obrist B (2012) Timing of antenatal care for adolescent and adult pregnant women in South-eastern Tanzania. BMC Pregnancy and Childbirth 12: 16. 